\title{
An Urgent Need for Investment in Health Management Education
}

\section{Godfrey Isouard*}

School of Health, University of New England, Australia

\section{Introduction}

Internationally the agenda for healthcare reform has moved rapidly. In Australia, the health care system has recently undergone significant structural changes to target sustainable improvements to the performance of health service delivery [1]. Throughout this process there has been growing attention to the importance that leadership and management can play in the ultimate success of improved health service delivery [2]. The quality of the management and leadership education within the health services and state health authorities has been shown to be crucial to better patient outcomes [3].

Despite leadership being integral to the success of reform, the national strategies have failed to address the leadership and management education, development and training needed at the health care and health services level. The Australian health service reforms ignore the critical issues of planning and investment towards the education and development required for a system targeting management and decision making at the hospital level [4].

The two prominent professional bodies which nationally promote health management education, research and professional development are the Society for Health Administration Programs in Education (SHAPE) and the Australasian College of Health Service Management (ACHSM). Both groups have recently sought commitment from the government, health departments and healthcare providers to invest in health management education through supporting the continuing professional development and training of the health management workforce $[5,6]$.

\section{SHAPE Declaration}

The mission of SHAPE is the promotion of excellence in health management education and research in Australia, New Zealand, Asia and the Pacific. The recently developed SHAPE Declaration provides a number of guiding principles which define the profession's position on health reform in terms of policy, systems enhancement, service delivery and governance [7]. The SHAPE Declaration includes provision for minimum standards of health management education, structured work-based training and experience, and continuing professional development of the workforce. The central importance of health service managers and the need for government commitment to their education and development are included as critical components for successful health reform implementation.

\section{Health Management Education}

The important areas for consideration in developing health management education include: the qualifications and credentialing of health service managers; the need for significant investment into health management education, leadership and continuing professional development of the health management workforce. Education and learning is delivered in many ways, including formal course work study, the use of role models and mentors, work-based informal learning, and continuing professional development.

A recent study reported that health managers had higher levels of education than the average for all industries with $55.8 \%$ having either an undergraduate or postgraduate qualification. In particular, it was found that hospital managers had a high proportion (29.9\%) of postgraduate qualifications compared with managers in medical and other health services $(20.7 \%)$ [8].

Health managers and leaders generally work in overlapping clinical and other professional roles in areas of management, administration, planning and policy. The role is often complex and involves several components of planning, mobilisation, directing, controlling, coordinating, performance management, and supervising the delivery of health and social services in various settings. These areas of work may include clinical management, human resource management; finance and operations; practice management, purchasing, contracting, facilities, and information management and technology [9].

Programs in health management education and training prepare future health managers to deal with the needs arising from the growing impact of chronic disease, an ageing population, technological innovations, an increasingly complex regulatory environment, an increased focus on primary and preventive care, and the issues of access and equity, and safety and quality [5].

The SHAPE Declaration had endorsed five principles on how health services could be best organised and effectively managed [7,10]:

- Public policy must focus on improving health outcomes through the provision of frameworks of responsibility and cooperation;

- Health reforms should focus on the needs of communities and populations, and structural arrangements then determined accordingly;

- Providers should meet the diversity of need and exhibit good governance and management achieved from proper engagement of structural interests;

- Effective models of community engagement need to be used when determining the policy and governance of health services;

- Health managers should be appropriately qualified, skilled and adept in managing complex health service organisations.

\section{Accreditation of Programs}

Accreditation is ultimately designed to foster high quality professional education for healthcare professionals. It plays an important role in establishing the appropriate professional development framework for the health management workforce into the future. In

*Corresponding author: Godfrey Isouard, School of Health, University of New England, Armidale NSW 2351, Australia, E-mail: gisouard@une.edu.au

Received December 26, 2012; Accepted December 27, 2012; Published December 29, 2012

Citation: Isouard G (2012) An Urgent Need for Investment in Health Management Education. J Biosafety Health Educ 1:e106. doi:10.4172/2332-0893.1000e106

Copyright: (c) 2012 Isouard G. This is an open-access article distributed under the terms of the Creative Commons Attribution License, which permits unrestricted use, distribution, and reproduction in any medium, provided the original author and source are credited. 
doing so, it assures students and other stakeholders that the health management education program meets established standards of quality, uses industry relevant and current academic content, and, includes membership in a network of professional colleagues.

In Australia, the ACHSM is the accrediting body for the accreditation of health management programs in education. Its mission is defined as the commitment to ensuring that graduates from health services management programs at participating universities have the recognised attributes to meet the challenges of leading and managing within the heath sector [11]

The ACHSM Accreditation Program utilises a set of agreed standards which have been established to assess the major capabilities health management programs would need to address in their course content. These are grouped into the following categories [11]:

- Core knowledge and skills for all managers. As examples: financial and human resource management, strategic thinking and planning, basic organisational management, and organisational change;

- Core knowledge and skills for health managers. As examples, understanding the health system, clinical governance, quality, safety, and health policy and reform;

- Specific technical health management skills. As examples, service planning, case mix management, and infrastructure management;

- Core relationship skills. As examples, working with others, building and negotiating stakeholder relationships, influencing and facilitating, and interpersonal communication skills;

- Core personal attributes. As examples, self- awareness and selfmanagement.

The ACHSM defines an overview of capabilities required of health managers and outlines the knowledge, skills and attributes expected of graduates. The ACHSM further provides an overview of the range of learning and teaching strategies likely to be used to allow the capabilities to be developed [11].

The ACHSM identifies how the curriculum of a health management education program may be structured to develop the knowledge, skills and attributes required for a health manager. These targeted knowledge, skills and attributes include: problem solving, analytical skills, managing others, managing self, strategic and systems thinking, continuous learning, and interprofessional practice [11]

\section{The Challenges Ahead}

The following are some recommended strategies that need to be planned for and considered to address the challenges reported in the delivery of health management education programs:

1. To regularly review programs to ensure their relevance and currency in the domestic and international markets;

2. Undertake as required a comprehensive curriculum review through which innovative approaches to teaching, learning and research are adopted;

3. Maintain strong connections and partnerships with community, industry and professional bodies to enable the program to achieve regional and global impact. This is largely undertaken through a close working relationship with the program's External Advisory Board;

4. Facilitate networking with business, industry and the community to leverage support for the University or College, provide opportunities for research collaborations, and provide vocational experience for student placements;

5. Provide appropriate advice on the relevance of courses to prospective students, the community, to industry, and to appropriate professional bodies, adopting open and transparent processes;

6. To integrate the formal program of study with the use of work-based role modelling and mentoring, workplace learning, and continuing professional development.

7. Addressing these and other challenges would assist in the overall achievement of preparing graduates who are valued by employers and able to make a difference within their workplace and communities.

\section{References}

1. A National Health and Hospitals Network for Australia's Future (2010) Commonwealth of Australia.

2. A Healthier Future for All Australians: National Health and Hospitals Reform Commission - Final Report June 2009 (2009) Commonwealth of Australia.

3. Isouard G (2010) Leading and managing the implementation process: the key to successful national health reform. Asia Pacific J Health Manag 5: 11-16.

4. Isouard G (2010) National health reform success: it's all about leadership and management. Australian Quarterly 82: 3-6.

5. Isouard G (2008) A real opportunity for SHAPE and the ACHSE to lead the national debate for health system reform. Asia Pacific J of Health Manag 3: 4-5

6. Grima R (2008) Informed public debate on the management and direction of the Australian Healthcare system. Asia Pacific Journal of Health Manag 3: 5.

7. Briggs DS (2008) SHAPE Declaration on the organisation and management of health services: a call for informed public debate. Asia Pacific J Health Manag 3: $10-13$.

8. Martins JM, Isouard G (2012) Health Service Managers in Australia Part 3 field of study, level of education and income. Asia Pacific $\mathrm{J}$ of Health Manag 7: 43-58.

9. Martins JM, Isouard G (2012) Health Service Managers in Australia Part 1 service, geographical and category distribution. Asia Pacific J of Health Manag 7: 16-28.

10. Briggs DS, Smyth A Anderson JA (2012) In Search of Capable Health Managers: what is distinctive about health management and why does it matter? Asia Pacific J of Health Manag 7: 71-78.

11. ACHSM accreditation program policy and manual (2012) ACHSM Australia. 